\title{
A linguagem científica na escola - proposições para um "olhar etnográfico" sobre livros didáticos em ciências
}

\author{
Lenguaje científico en la escuela: propuestas para una "mirada \\ etnográfica" sobre los libros didácticos de ciencias \\ Scientific Language in the School: Proposals for an "Ethnographic Look" \\ on the Books of Science Text
}

Ma. Paula Simone Busko ${ }^{1}$

\begin{abstract}
Resumo
O artigo tem o objetivo de explicitar a importância de um "olhar etnográfico" sobre livros didáticos em ciências nas escolas brasileiras. Conceitualmente, faz-se necessário esclarecer o que é uma pesquisa etnográfica e seus fundamentos, o que indica para o campo teórico da etnografia os conceitos de Clifford Geertz e para a linguagem os conceitos de Michel Pêcheux e Eni Orlandi. Em um trabalho de análise mais elaborado com os professores, descrever ou interpretar a linguagem dos livros didáticos é desafiar a ciência "tal qual se faz", procurando encontrar novas formas de ensinar ciências.
\end{abstract}

Palavras-chave: linguagem, etnografia, livro didático.

\section{Resumen}

El artículo tiene como objetivo aclarar la importancia de una "mirada etnográfica" sobre los libros de texto de ciencias en las escuelas brasileñas. Conceptualmente, es necesario aclarar qué es una investigación etnográfica y sus fundamentos, lo que indica al campo teórico de la etnografía los conceptos de Clifford Geertz y al lenguaje los conceptos de Michel Pêcheux y Eni Orlandi. En un trabajo de análisis más elaborado con los maestros, describir o interpretar el lenguaje de los libros de texto es un desafío para la ciencia "tal como es", buscando nuevas formas de enseñar ciencia.

Palabras clave: lenguaje, etnografía, libro de texto.

\begin{abstract}
The article aims to make explicit the importance of an "ethnographic look" on textbooks in science in Brazilian schools. Conceptually, it is necessary to clarify what is an ethnographic research and its foundations, which indicates for the theoretical field of ethnography the concepts of Clifford Geertz and for the language the concepts of Michel Pêcheux and Eni Orlandi. In a more elaborate analytical work with teachers, describing or interpreting the language of textbooks is challenging science "as it is," seeking to find new ways of teaching science.
\end{abstract}

Keywords: language, ethnography, textbook.

\footnotetext{
1 Doutoranda em Educação Científica e Tecnológica (PPGECT-UFSC); Mestre em Educação e Formação História, Política e Gestão das Instituições Escolares (UNISANTOS-SP); Especialização em Educação Ambiental e Especialização em Marketing; Participação em Grupos de Pesquisa da UFSC: DICITE (Discursos da Ciência e Tecnologia) e Literaciências (Literatura, Decolonialidade e Ensino de Ciências).paulabusko@gmail.com.
} 


\section{Introdução}

O artigo tem o objetivo de explicitar a importância de um "olhar etnográfico" sobre livros didáticos em ciências nas escolas brasileiras. De modo específico, este olhar tem o intuito de alertar para certas práticas de linguagem estabelecidas, além de propor a descolonização do ensino universalizado e positivista das ciências em geral.

Evidencia-se o uso de uma linguagem específica no âmbito das ciências, amplamente difundida em seus livros didáticos. Linguagem ideologicamente formatada para o aprendizado escolar em que professores e alunos tornam-se ancorados nos saberes padronizados e atemporais. Este "não movimento" de mudança no ensino de ciências se dá, em parte, pela intervenção das políticas públicas em educação, o que acaba por definir o lugar da universalização da popularização das ciências no contexto evolutivo das ciências mundiais.

Questiona-se o papel da escola e da formação continuada dos professores de ciências e das políticas linguísticas que atravessam os conteúdos escolares. Além de uma linguagem científica universalizada e enraizada nos conteúdos de biologia, química ou astronomia, por exemplo, observa-se a falta de capacitação/formação continuada de professores em seus campos de saberes, o que reflete uma carência no aprendizado escolar.

Um "olhar etnográfico" sobre os livros didáticos por parte do professorado talvez trouxesse um novo olhar sobre a linguagem ali ajustada. Esse novo olhar parte de uma série de premissas que serão apontadas no decorrer da exposição, trazendo ao debate novas possibilidades para o ensino de ciências, a exemplo da própria linguagem, como forma de contextualizar um novo discurso sobre o que está posto. De forma dialógica, propõe-se questionar a universalidade de "verdades absolutas" no ensino de ciências.

Ao trazer novas possibilidades para o ensino de ciências, evidencia-se um trabalho de descolonização do saber universal. A tarefa de propor outras formas de construir o conhecimento não é fácil diante de uma ciência dita pós-moderna, que insiste em manter seu status quo. Conforme Maldonado-Torres (2010): "As vozes que vêm do Norte vêm sempre carregadas de autoridade histórica, esbravejando sua notoriedade legitimada por seu lugar de pertencimento, ainda exigindo seu espaço de destaque".

Conceitualmente, faz-se necessário esclarecer o que é uma pesquisa etnográfica e seus fundamentos, o que indica para o campo teórico da etnografia os conceitos de Clifford Geertz e para a linguagem os conceitos de Michel Pêcheux e Eni Orlandi. Nesse contexto, dar exemplos de como uma linguagem universal se apresenta em alguns livros didáticos no Brasil e das formas de analisar criticamente tais saberes. 
Metodologicamente, é propor um olhar descritivo e crítico por parte dos professores sobre os conteúdos escolares em ciências, seja por meio de reuniões, oficinas pedagógicas ou seminários de formação continuada.

\section{Etnografia e formação de professores.}

A carência de debates para a formação continuada em ciências é assunto cada vez mais debatido nas escolas e pela sociedade. Infelizmente, considerando que os modelos tradicionais da organização curricular não atende as expectativas dos professores em relação às exigências sobre sua capacitação, muitos professores acabam por se formar mais com outros professores no interior das próprias escolas do que nas universidades e institutos de formação (CHARLOT, 2002).

De certo modo, políticas públicas em relação aos conteúdos de ciências têm objetivado propostas de melhorias nas escolas. Isso ocorre em relação aos laboratórios de ciências e visitas técnicas a museus e feiras, por exemplo; quanto aos conteúdos didáticos, estes são regularmente debatidos pelos professores, o que, de certo modo, deveria trazer uma gama de atualizações no âmbito das pesquisas científicas (retroalimentação). Teoricamente. Na prática, os responsáveis pela implantação de melhorias nos currículos nas escolas argumentam a falta de recursos orçamentários. Além disso, muitos professores responsáveis por trazer novos conteúdos não veem a necessidade de atualização.

Enquanto esse debate não traz a movência necessária ao ensino de ciências, trago em evidência a fala de Rampton, Maybin e Roberts $(2014$, p. 6) ao afirmarem que a etnografia “tem ganhado peso nos estudos da linguagem, de modo que já não é mais um método de coleta de dados suplementar". Ou seja, estudos da etnografia baseados em textos no ensino promovem a busca de resolução de falhas em outros campos do saber relacionados à educação. Sendo assim, “a linguística passa a recurso operacional precioso por sua capacidade de identificar movimentos sutis de negociação prática das relações sociais" (RAMPTON et. al., 2014, p. 6).

Em realidade, quando se trata de uma pesquisa etnográfica, não há fatos a serem colhidos. Para um etnógrafo, fazer etnografia é trabalhar sobre o denso em que poderão ser encontradas sem sentido. É propor um olhar mais apurado sobre livros e textos que muitas vezes não revelam seus silêncios. Tudo pode ser subjetivo. Muitas falas não dão margem a uma reflexão, nesse sentido, é preciso ter paciência, criar familiaridades e propor outro olhar 
sobre a materialidade do texto. Para entender sua linguagem e seus sentidos, Geertz afirma que,

\begin{abstract}
a etnografia é uma descrição densa. O que o etnógrafo enfrenta, de fato - a não ser quando (como deve fazer, naturalmente) está seguindo as rotinas mais automatizadas de coletar dados - é uma multiplicidade de estruturas conceptuais complexas, muitas delas sobrepostas ou amarradas umas às outras, que são simultaneamente estranhas, irregulares, inexplícitas, e que ele tem que, de alguma forma, primeiro apreender e depois apresentar (...) Fazer etnografia é como tentar ler (no sentido de 'construir uma leitura de') um manuscrito estranho, desbotado, cheio de elipses, incoerências, emendas suspeitas e comentários tendenciosos..." (GEERTZ, 2008, p.7).
\end{abstract}

Como um registro de uma cultura material, um trabalho etnográfico descreve costumes, modos de viver de um povo, suas crenças (inclusive a científica) e experiências. Outra questão importante são as condições materiais de pesquisa e as possibilidades de convivência com o grupo pesquisado.

A partir do trabalho de Malinowski, o antropólogo passou a ter a obrigação de libertarse do "etnocentrismo" (a tendência que todos temos de interpretar o outro com base em nossos próprios valores e crenças) e "relativizar" os diferentes costumes e visões de mundo, respeitando as características de cada contexto cultural específico. Para tanto, o pesquisador precisa de uma longa e profunda convivência com o grupo social que deseja compreender.

Metodologicamente, é crucial que o etnógrafo ou o pesquisador não estabeleça um modo de olhar etnocêntrico para suas interpretações, pois corre o risco de seu trabalho não ser condizente com os objetivos de suas análises.

Não resta dúvida de que a subjetividade do observador interfere de modo mais marcante em uma pesquisa do que uma coleta de dados etnográficos cristalizados. Porém, mesmo nesse particular, o pesquisador deve empenhar-se no sentido de deixar que "os fatos falam por si mesmos" (MALINOWSKI, 1976).

Mas como associar etnografia à escola? Santos, M-E (1999; 2005), argumenta que esta área de estudos é integradora a vários níveis e campos do conhecimento. Ou seja, a etnografia não trata somente de conteúdos específicos. Para o autor, ela atravessa vários campos do saber e carrega consigo muitos outros elementos de análises, sínteses, avaliações e articula-se com o social - onde está a escola entre outras instituições. Sem dúvida, a etnografia articula-se com a cidadania, pois leva o sujeito ao "conhecimento emancipação" (SANTOS, 1989). Portanto, a etnografia não pode ser considerada uma disciplina fechada em si mesma, sem articulação com outras áreas do saber, sobretudo com a escola e com os processos de linguagem. 


\subsection{A pesquisa etnográfica na escola: modelos de análises.}

Mas como realizar uma pesquisa etnográfica no campo escolar? Primeiramente, um trabalho etnográfico na escola consiste em coletar dados de determinados livros e textos utilizados no ensino de ciências, principalmente dos que tratam da natureza da ciência e da biologia. Em segundo, é contextualizar seu período histórico, o sujeito-autor do texto e suas justificativas.

As bases conceituais utilizadas e a linguagem - palavras, frases - que retratam um modelo cultural científico já posto delimita a fala do texto. Desse modo, não há possibilidades de desvios de interpretação por parte dos alunos. Nessa proposta, os dados coletados são predominantemente uma descrição etnográfica. Assim,

há três características da descrição etnográfica: ela é interpretativa; o que ela interpreta é o fluxo do discurso social e a interpretação envolvida consiste em tentar salvar o "dito" num tal discurso da sua possibilidade de extinguir-se e fixá-lo em formas pesquisáveis (GEERTZ, 2008, p. 16).

Esta descrição etnográfica antecede uma análise mais elaborada que posteriormente irá tratar dos discursos científicos. Sabe-se que os fatos científicos que serão descritos dos livros e textos são dados construídos por outras pessoas e no caso de uma interpretação deve-se ter em mente que ela vem de um discurso social ali estabelecido. Nos estudos realizados para uma pesquisa em etnografia da linguagem percebe-se que um discurso científico é antes de tudo um discurso social. Remete há um tempo, um lugar e a um sujeito que fala. Desse modo,

o etnógrafo "inscreve" o discurso social: ele o anota. Ao fazê-lo, ele o transforma de acontecimento passado, que existe apenas em seu próprio momento de ocorrência, em um relato, que existe em sua inscrição e que pode ser consultado novamente (GEERTZ, 2008, p. 14).

Portanto, compreender o discurso social do que está presente nos livros didáticos e extrair uma análise com base na etnografia do discurso social ali presente, não é por vezes tarefa fácil. No que tange as políticas linguísticas e utilizando-se da linguagem como “intervenção", pergunta-se:

Por que as pessoas optam por usar (ou deixam de usar) linguagens e variedades específicas para funções especificadas em diferentes domínios, e como essas escolhas influenciam - e como elas são influenciadas pela tomada de decisões institucionais de política de linguagem - local para nacional e supranacional? (RICENTO, 2000, p. 208) 
No âmbito da biologia, por exemplo, estudos da seleção natural proposta por Charles Darwin questionam o modelo cristão criacionista ainda empregado em muitas escolas públicas. Outros exemplos estão relacionados ao eurocentrismo e aos processos de globalização que defendem o uso desenfreado dos recursos naturais.

O estudo dos biomas onde o homem não está separado da natureza em que vive é algo novo no ensino de ciências. Mas, em muitos livros é "apagado" ou nem questionado. Interpretar o fluxo do discurso social colonial, por exemplo, de que nossos índios "eram selvagens" e que "não tinham alma" e mais tarde "foram salvos" pela cristandade é uma verdade de uma época.

O modelo positivista ainda permanece com o ensinamento de que ainda há a separação do homem (dominante) da natureza (dominada). Encontram-se também termos como o progresso científico ou modernidade justificando a exploração do meio ambiente como forma de trazer a civilização aos países "subdesenvolvidos":

[...] a ciência, a objetividade, a neutralidade, o universalismo, a verdade, a realidade, a razão passam a ser entendidas em seu caráter particular de interesses normativos e de formas específicas de organizar a percepção e a comunicação a respeito do mundo. São todos concebidos como expressões ideológicas que legitimam relações de poder historicamente específicas (GIROUX, 1993).

Um trabalho de etnografia questionando e debatendo tais processos culturais poderá trazer o entendimento do que seria uma "descrição densa" (GEERTZ, 2008) daquela realidade, mas trazida para nosso momento histórico através dos materiais escolares. Para colocar um exemplo simples de uma descrição de um livro didático e o que está aí silenciado coloco a fala de

Bordieu e Passeron na afirmativa de que "o currículo da escola está baseado na cultura dominante: ele se expressa na linguagem dominante, ele é transmitido através do código cultural dominante". Ao utilizarmos qualquer ferramenta de busca em internet com as palavras "cientista" e "ciências", as imagens mais frequentes caracterizam o sujeito universal: o homem branco em seu laboratório (Figura 1) (BENITE, 2016, p.735). 


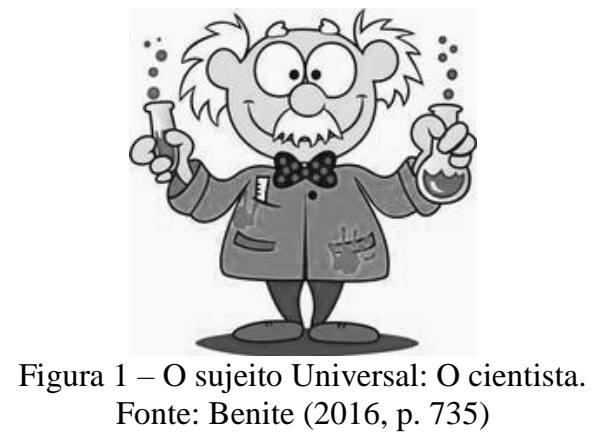

De acordo com Benite (2016, p. 735), o cientista universal é sempre posto de uma mesma forma: senhor, cabelos brancos, sem falar no bigode, é um homem, que usa avental sujo devido muitos experimentos, presente na maioria dos livros didáticos.

Todos estes exemplos carregam em seus textos uma cultura, uma memória e uma ideologia. Neste processo a linguagem a ser descrita busca a interpretação do seria o "conhecimento verdadeiro", esta linguagem frequentemente pode ser descrita representando o que deveria ser o mundo. Sem estabelecer o certo ou o errado, busca uma cultura globalizante, articulada e fixa.

Apresento aqui outro exemplo do que poderíamos estabelecer no âmbito de uma análise sobre um livro de química para o Ensino Médio e das imagens associadas ao título do capítulo intitulado A Bomba de Chocolate (Figura 2). Tem-se a figura de uma menina e de várias comidas apontadas como calóricas e que produzem o colesterol ruim. Poderia ser a figura de um menino, mas as imagens estabelecidas pelas autoras do capítulo Cebulski e Politano (2006, p. 163-164) não para por aí, pois em vários outros momentos mulheres são associadas ao impulso da fome e suas consequências. Isso traz uma memória e deve ser questionado e debatido. Ora, porque em várias partes do livro, a figura feminina está associada às coisas erradas?

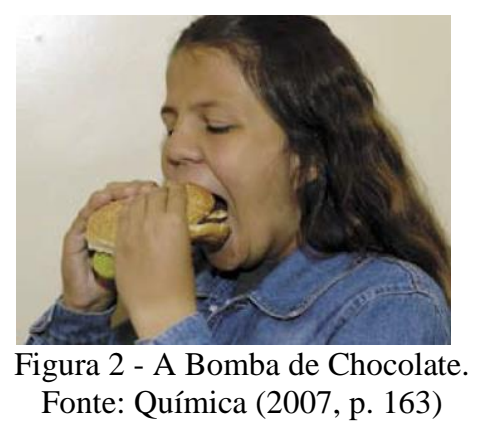

É correto afirmar, na visão de Santaella \& Nöth (2008), que as imagens historicamente produzidas na cultura científica tornam-se elementos da cultura escolar e de sua memória. É 
linguagem científica. E pode ser considerada representação de uma coisa que é percebida pelos sentidos. Imago, no latim, significa imagens associadas à sombra, à figura, à uma imitação ou a uma representação figurada relacionada a um objeto. Portanto, temos imagens sonoras, táteis, olfativas e visuais. A imagem se torna algo material e convencional quando aplicada a um contexto específico.

Discutir as origens de um pensamento científico, em contraponto ao senso comum, aos mitos, a religião, enfim, ao cotidiano que alunos e professores trazem de "seus mundos" externos é de suma importância, o que ajuda na compreensão de novas possibilidades de enxergar à aprendizagem escolar.

Em outro livro, de Sociologia (2006) para o Ensino Médio, capítulo 1, Lorensetti faz abordagem à Rubem Alves que conceituou o senso comum em relação à ciência:” Para muitas pessoas, passar por debaixo de uma escada traz azar (Figura 3). Crenças como essa, também podem ser um exemplo de senso comum" (2006, p. 19).

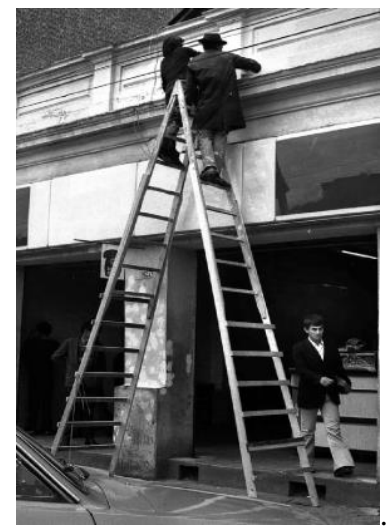

Figura 3 - O surgimento da Sociologia e Teorias Sociológicas. Fonte: Sociologia (2007, p. 19)

Nessa linha de pensamento, a linguista Eni Orlandi argumenta que há um tipo de silêncio constitutivo, ou seja, para dizer algo é preciso não dizer, que é a inserção dos sujeitos discursivos nas formações discursivas historicamente determinadas que dêem sentidos ao dizer. É esse silêncio constitutivo que trabalha os limites e a constituição das formações discursivas (regiões de sentidos), determinando os limites do dizer. Isso mostra que o dizer e o silenciamento são inseparáveis (ORLANDI, 2007). 


\section{Um "olhar etnográfico" nos conteúdos das ciências universais: descolonizando saberes.}

Para que se possam analisar diferentes discursos científicos que circulam nas escolas se fazem necessário, primeiramente, coletar e descrever (como um trabalho de campo) os aspectos da linguagem inerentes aos textos presentes nos livros didáticos. Seria realizar análises mais aproximadas do que está presente e de como estes textos, através da linguagem, trazem uma forma de pensar e interferem em uma determinada realidade escolar.

Em um trabalho de análise mais elaborado com os professores, descrever ou interpretar a linguagem dos livros didáticos é desafiar a ciência "tal qual se faz", procurando encontrar novas formas de ensinar ciências. Sem dúvida, é propor a eles que um olhar mais apurado ou mesmo crítico sobre o que está posto pela ciência positiva, através de certas políticas linguísticas, corrobora para novas formas de preparar alunos cidadãos para uma reflexão crítica sobre ciências. Este processo pode ser feito com a formação de rodas de conversa entre professores de ciências, pedagogos, linguistas, etnógrafos, além de seminários abertos de formação de professores, oficinas pedagógicas ou reuniões formais ou informais de professores da escola ou fora dela.

Um ponto em destaque nessas discussões são as relações sociais e históricas nas quais os livros didáticos se constroem. Condições de produção. A linguista Eni Orlandi argumenta que há um tipo de silêncio constitutivo, ou seja, para dizer algo é preciso não-dizer, que é a inserção dos sujeitos discursivos nas formações discursivas historicamente determinadas que dão sentidos ao dizer. É esse silêncio constitutivo que trabalha os limites e a constituição das formações discursivas (regiões de sentidos), determinando os limites do dizer. Isso mostra que o dizer e o silenciamento são inseparáveis (ORLANDI, 2007).

A partir daí, utilizando o referencial da análise do discurso, pode-se abrir um debate para a compreensão pública da ciência e de como ocorre o engajamento por parte da escola e da sociedade por livros e textos. O material a ser obtido nessas pesquisas é rico em linguagem, formal e coloquial, nas descrições de pessoas, nos fatos narrados de situações, nas fotografias, nos desenhos de experimentos científicos e extratos de vários tipos de documentos que devem passar por uma descrição e interpretação etnográfica.

Outra metodologia possível de descrever uma linguagem presente nos materiais a serem utilizados em meu trabalho estaria em Bakhtin. Como precursor de uma teoria enunciativodiscursiva que considera a linguagem como uma atividade, instituída em um processo 
concreto em que o signo se instaura de maneira ideológica e dialogicamente, os signos linguísticos não estaria em um sistema fechado, mas sempre em constante circulação:

\begin{abstract}
em outras palavras, há um sistema ampliado, cujos signos existem somente em interação verbal, como enunciado, em gêneros discursivos, que possibilitam a compreensão de diferentes organizações enunciativo-discursivas, assim, como a compreensão das características repetíveis, formais da linguagem, que se convertem em diferentes sentidos (FANTI, 2003, p. 99).
\end{abstract}

Diante deste pressuposto, a linguagem não é um fim em si mesmo. Ela circula, sugere interpretações (que está na subjetividade do etnógrafo-pesquisador). Devemos tratá-la como um movimento de interação, pois mesmo nos discursos científicos, há uma saída, há sentidos que poderão ser produzidos. Por isso considerar a linguagem como discurso, em Bakhtin, é reconhecer a sua "dialogicidade interna", já que não é a forma composicional externa que vai determinar o teor dialógico (BAKHTIN, 1998, p. 92).

Quero com isto dizer que todos somos sujeitos históricos. Para Bakhtin, portanto, existe uma relação entre o sujeito, que não deixa de ser determinado, e o processo histórico no qual está inserido. Articular a dimensão histórica da formativa nos processos de análise é alcançar as políticas linguísticas impostas pelos discursos. O gênero discursivo a que se destacam os enunciados se manifesta entre o "novo" (discurso) e o "velho", como uma forma concreta e histórica, perpetuando os modelos sociais existentes.

Conforme proposto por Rampton, Maybin e Roberts (2014, p. 21), uma análise de textos visuais e escritos resultantes de etnografias da linguagem colaborativas empreendidas com profissionais de educação, saúde, justiça etc. estabelecem um movimento aberto entre o trabalho teórico, descritivo e intervencionista, e que haja diálogo contínuo ou mesmo trabalho em equipe realmente entre pessoas com essas inclinações diferentes, mas complementares.

Em vista dessas questões, um olhar etnográfico sugere as seguintes proposições:

a. Desafiar as barreiras conceituais da ciência universal e descolonizar a linguagem, questionando quais saberes reflete e refrata no social;

b. Quais aspectos culturais de produção de conhecimento envolvidos no contexto das falas, imagens e símbolos propostos na textualização dos livros analisados;

c. Questionar as políticas linguísticas inseridas no contexto das políticas públicas em educação;

d. Qual nossa gênese atual e quais outros possíveis discursos a serem refeitos na proposição de recriar sentidos outros para o ensino. 
Fica claro que uma das principais contribuições da etnografia da linguagem é preparar nossos olhares para os cenários escolares, ajudando os professores a compreender certos caminhos utilizados pela educação pública contemporânea. É pensar a formação de professores a partir de um posicionamento político linguístico e procurar fazer de "outro modo", descolonizando os saberes universalizados.

Cada vez mais, formadores de professores, linguistas, etnógrafos procuram adotar uma visão social construtivista de que "a realidade humana é extensamente reproduzida e criada de novo nas atividades social e historicamente específicas da vida cotidiana" (RAMPTON, 2000, 10). Corroboram-se, nesse contexto, implicações sobre como interpretamos os livros e nossa política curricular vigente. Apropriar-se com um olhar crítico sobre o que está posto é ter em mente que há padrões do uso da linguagem, das relações sociais e de poder que devem ser questionados.

\section{Conclusões}

Este artigo procurou trazer à reflexão a contribuição da etnografia para a investigação do uso da linguagem aplicada no ensino de ciências. O intuito de debater como, através de um aporte metodológico sistematizado neste espaço, uma determinada linguagem utilizada como intervenção pode ajudar ou não no aprendizado de ciências nas escolas. O livro didático, objeto de análise dessa temática, proporciona o fazer investigativo por parte dos professores, que poderão compreender o cenário em que são construídos certos saberes.

A escola, por excelência, é o local ideal para divulgar ideias novas e para o desenvolvimento de ações que envolvam diversos temas. $\mathrm{O}$ uso dos livros e de textos no ensino de ciências promove, de certo modo, o encontro entre o discurso científico e a sala de aula. Para um trabalho de pesquisa etnográfico mais elaborado em que se façam abordagens sobre os aspectos culturais, sobretudo da linguagem, e dos processos de colonização no ensino não se pode deixar de lado o modo em como são coletados estes materiais, nem a fala e nem o gênero discursivo envolvidos neste âmbito.

No âmbito dos estudos da linguística aplicada o papel da etnografia tem demonstrado seu valor, o que pressupõe que certas práticas de linguagem e das várias textualizações apresentadas pelos livros didáticos trazem a viabilidade de um olhar mais atento sobre essas interlocuções linguagem-etnografia. 
De qualquer modo, um trabalho etnográfico sobre os discursos científicos estabelecidos nos livros e textos didáticos para o ensino de ciências não sugere julgamentos do que ali está posto como o certo ou o errado, mas sim tornar público como determinados materiais de ensino constituem certas linguagens que produzem "verdades" e "silêncios" (o que está por trás do discurso).

Estabelecer uma etnografia da linguagem é essencial para que se possa considerar a relação existente entre linguagem e sociedade, assim como suas funções, valorizando os aspectos culturais existentes em cada fala. Sem a linguagem também não há ciência, pois esta precisa ser divulgada, traçando regras para um mundo social e cultural nos discursos científicos.

\section{Referências}

BAKHTIN, M. O discurso no romance. In: Questões de literatura e de estética: a teoria do romance (1934-1935). Trad. Bernadini et al. 4. ed. São Paulo: Unesp, 1998. p.71-210.

BENITE, A. M. C., SILVA, J. P., ALVINO, A.C., Ferro, Ferreiros e Forja: O Ensino de Química pela Lei No 10.639/03. In: OLIVEIRA, J. M. (Org.). In: Educação em Foco. v. 21. n. 3. Universidade Federal de Juiz de Fora (UFJF), 2016.

CHARLOT, B. Formação de professores: a pesquisa e a política educacional. In: PIMENTA, S.; GHEDIN, E.. Professor reflexivo no Brasil: gênese e crítica de um conceito. São Paulo: Cortez, 2002. p. 89-108.

FANTI, M.G. C. A linguagem em Bakhtin: pontos e pespontos. Veredas. Revista Est. Linguagem, Juiz de Fora, v.7, n.1 e n.2, p.95-111, jan./dez. 2003.

GEERTZ, C. A interpretação das culturas. Rio de Janeiro: LTC, 2008, 323p.

GIROUX, H. O Pós-modernismo e o discurso da crítica educacional. In: SILVA, T.T. da (Org.). In: Teoria Educacional Crítica em Tempos Pós-Modernos. Porto Alegre: Artes Médicas, 1993.

MALDONADO-TORRES, N. A topologia do Ser e a geopolítica do conhecimento. Modernidade, Império e Colonialidade. In: SANTOS, Boaventura de Sousa; MENESES, Maria Paula. Epistemologias do Sul. Coimbra-PT: Almedina, 2010, p. 399.

MALINOWSKI, B. Argonautas do Pacífico Ocidental. São Paulo: Abril, 1976.

ORLANDI, E. P. As formas do silêncio. Campinas: UNICAMP, 2007.

QUÍMICA. Vários autores. Ensino médio, 2a . ed.. Curitiba: SEED-PR, 2006. p. 248. Disponível em: <http://www.educadores.diaadia.pr.gov.br/arquivos/File/livro_didatico/ quimica.pdf > Acesso em 21 de jul. 2019. 
RAMPTON, B., MAYBIN, J., ROBERTS, C. Methodological foundations in linguistic ethnography. In: Working Papers in Urban Language and Literacies . 2014. King's College London. Disponível em:

$<$ https://www.kcl.ac.uk/sspp/departments/education/research/Research-

Centres/ldc/publications/workingpapers/abstracts/WP125--Methodological-foundations-inlinguistic-ethnography.aspx> Acesso em: 23 de abr. 2019.

RICENTO, T. Historical and Theoretical Perspectives in Language Policy and Planning. In: Journal of Sociolinguistics. Maio, 2000, p. 235. Disponível em:

$<$ https://www.researchgate.net/publication/227549507_Historical_and_Theoretical_Perspecti ves_in_Language_Policy_and_Planning> Acesso em 23 de jun. 2019.

SANTAELlA, L. ; NÖTH, W. Imagem - Cognição, Semiótica, Mídia. São Paulo: Iluminuras, 1998.

SANTOS, B. Introdução a uma ciência pós-moderna. Porto: Afrontamento, 1989.

SANTOS, M-E. Desafios pedagógicos para o século XXI. Lisboa: Horizonte, 1999.

SANTOS, M-E. Cidadania, conhecimento e educação CTS. Rumo a novas dimensões epistemológicas. Revista Iberoamericana de Ciencia, Tecnologia y Sociedad-CTS, V.6, 2005.

SOCIOLOGIA. Vários autores. Ensino Médio, 2a . ed. Curitiba: SEED-PR, 2006. 266 p. Disponível em: <http://www.educadores.diaadia.pr.gov.br/arquivos/File/livro_didatico/ sociologia.pdf >. Acesso em 19 de abr. 2019. 